\title{
Effects of sevoflurane versus propofol on cerebrovascular reactivity to carbon dioxide during laparoscopic surgery
}

This article was published in the following Dove Press journal:

Therapeutics and Clinical Risk Management

10 October 2017

Number of times this article has been viewed

\author{
Chunyi Wangl,* \\ Cheng $\mathrm{Ni}^{1, *}$ \\ Gang $\mathrm{Li}^{\prime}$ \\ Yan $\mathrm{Li}^{\prime}$ \\ Liyuan Tao ${ }^{2}$ \\ $\mathrm{Nan} \mathrm{Li}^{2}$ \\ Jun Wang' \\ Xiangyang Guo' \\ 'Department of Anesthesiology, \\ ${ }^{2}$ Research Center of Clinical \\ Epidemiology, Peking University Third \\ Hospital, Beijing, China \\ *These authors contributed equally \\ to this work
}

Correspondence: Xiangyang Guo; Jun Wang

Department of Anesthesiology, Peking

University Third Hospital, 49 North

Garden Rd., Haidian District, Beijing

I0019I, China

Tel/fax +86 I0 82267276

Email puthmzk@I63.com;

luckyoldhorse@sina.com
Purpose: Cerebrovascular reactivity to carbon dioxide $\left(\mathrm{CVR}-\mathrm{CO}_{2}\right)$ reflects cerebrovascular reserve capacity, which is important in many brain disorders, including cerebrovascular and Alzheimer's diseases. Meanwhile, there is a relationship between $\mathrm{CVR}-\mathrm{CO}_{2}$ and cognitive function. Therefore, the study is aimed at investigating the effects of sevoflurane versus propofol on CVR- $\mathrm{CO}_{2}$ during laparoscopic surgery, as well as the role of CVR- $\mathrm{CO}_{2}$ on cognitive function during perioperative period.

Patients and methods: Eighty-eight patients, aged 18-65 years undergoing elective laparoscopic cholecystectomy, were randomly assigned to group S and group P. The patients in group $\mathrm{S}$ were induced with propofol and maintained with sevoflurane. The patients in group $\mathrm{P}$ were induced and maintained with propofol (target-controlled infusion). Remifentanil was given to both groups. CVR-CO ${ }_{2}$ at baseline (before induction), before pneumoperitoneum and during pneumoperitoneum, as well as Mini-Mental State Examination scores at baseline and 24 hours after surgery were recorded.

Results: In group $\mathrm{S}, \mathrm{CVR}-\mathrm{CO}_{2}$ before and during pneumoperitoneum increased significantly compared with baseline $(P<0.05)$. In group $\mathrm{P}, \mathrm{CVR}-\mathrm{CO}_{2}$ before pneumoperitoneum increased significantly $(P<0.05)$, but $\mathrm{CVR}-\mathrm{CO}_{2}$ during pneumoperitoneum was not different compared with baseline. In either group, there was no significant correlation between mean blood pressure and CVR-CO $\mathrm{C}_{2}$ during surgery, and there was no significant difference between Mini-Mental State Examination scores at baseline and 24 hours after surgery.

Conclusion: Sevoflurane could maintain $\mathrm{CVR}-\mathrm{CO}_{2}$ at a higher level during pneumoperitoneum in surgery. Therefore, in patients with impaired cerebrovascular reserve capacity, inhaled anesthetic could be a priority strategy for anesthesia maintenance to improve the compensatory vasodilation ability of cerebral small vessels.

Keywords: cerebrovascular reactivity to carbon dioxide, sevoflurane, propofol, pneumoperitoneum, Mini-Mental State Examination score

\section{Introduction}

Cerebrovascular reactivity (CVR) was defined as the ability of small resistance arteries to constrict or dilate following the change of partial pressures of oxygen or partial pressures of carbon dioxide $\left(\mathrm{PaCO}_{2}\right)$, in which the latter was called CVR to carbon dioxide $\left(\mathrm{CVR}-\mathrm{CO}_{2}\right) .{ }^{1}$ In healthy people, with mean blood pressure (MBP) remaining constant, cerebral blood flow (CBF) increases linearly when $\mathrm{PaCO}_{2}$ increases in a specific range, and a study indicates that each $1 \mathrm{mmHg}$ increase in $\mathrm{PaCO}_{2}$ leads to an average $2 \%-4 \%$ increase in $\mathrm{CBF}$ in healthy people. ${ }^{2}$ Thus, $\mathrm{CVR}-\mathrm{CO}_{2}$ could reflect compensatory 
vasodilation ability of cerebral small vessels, ${ }^{3}$ which was also known as cerebrovascular reserve capacity.

CVR- $\mathrm{CO}_{2}$ decrease was related to many diseases, including cerebrovascular diseases, ${ }^{4-6}$ Alzheimer's disease ${ }^{7,8}$ and hypertension. ${ }^{9}$ Cerebrovascular disease has correlation with impaired CVR, and a study shows that reduced CVR was found in patients with lacunar infarct. ${ }^{6}$ Another study shows that impaired CVR predicted recurrent symptoms in patients with carotid artery occlusion, and those patients showed a higher risk of recurrent ischemic symptoms. ${ }^{5}$ In addition, a study in children with a prior diagnosis of transient cerebral arteriopathy showed that impaired CVR was limited to infarct zone and adjacent white matter in most children. ${ }^{4}$ Studies also indicated that CVR-CO $\mathrm{CO}_{2}$ declined in people with Alzheimer's disease, which was characterized by impaired

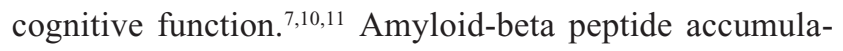
tion in blood vessels could cause vascular tone dysfunction, which was the main reason of its negative impact on CVR. ${ }^{8}$ Galanthamine, which was a commonly used medicine for Alzheimer's disease, could improve patients' CVR. ${ }^{7}$

CVR decrease might also be responsible for impaired cognitive function. ${ }^{12-14}$ A study shows that CVR was associated with Mini-Mental State Examination (MMSE) scores. ${ }^{12}$ Another study shows that after an elderly female patient with mild cognitive dysfunction and decreased CVR endured angioplasty, the CVR and MMSE score improved. ${ }^{14}$ In addition, a study showed that vascular impairment in regions of normal-appearing white matter that progressed to white matter hyperintensities (WMHs) consisted of decreased CVR, ${ }^{15}$ and $\mathrm{WMH}$ was demonstrated to be associated with cognitive decline $^{10}$ and dementia. ${ }^{16}$

Thus, the present study aims to investigate the effects of sevoflurane and propofol anesthesia on compensatory vasodilation ability of cerebral small vessels during laparoscopic surgery, and exploring a better anesthetic strategy for patients with impaired cerebrovascular reserve capacity, such as cerebrovascular patients.

\section{Patients and methods}

This experimental protocol was approved by Peking University Third Hospital Medical Ethics Committee (Number IRB00006761-2015176), and written informed consent was obtained from the patients. The patients aged in the range of 18-65 years undergoing elective laparoscopic cholecystectomy were enrolled in the study group. Inclusion criteria included physical status of I-II according to the American Society of Anesthesiologists and predicted surgery time of $\leq 2$ hours. Exclusion criteria included a history of psychiatric disorder, central nervous system disease, use of sedatives or antipsychotics, preoperative MMSE score $<24$ and difficulty in detecting transtemporal window with transcranial Doppler ultrasonic monitor.

Once the patients arrived at the operation room, the needles of Narcotrend (Narcotrend index [NI]) were attached to the foreheads, which could analyze electrocardiogram (EEG) and record anesthesia depth. Then, invasive BP, heart rate (HR), EEG and pulse oxymetry $\left(\mathrm{SpO}_{2}\right)$ were monitored and recorded. Before anesthesia induction, a special mask was put on to the patient's face, which connected a separate tube that could be attached to the sampling probe from a capnograph on transcranial Doppler monitor (Multi-Dop X; DWL, Sipplingen, Germany), thereby allowing for end-tidal $\mathrm{CO}_{2}$ tension $\left(\mathrm{PetCO}_{2}\right)$ monitoring. When patient was asked to breathe calmly, the expired gas was gathered in an air bag, which was connected to the mask; it was then inhaled by the patient again. The blood stream velocity spectrum of the middle cerebral artery was recorded simultaneously on TCD, including mean (Vmean), maximum (Vmax), minimum (Vmin) blood velocity of middle cerebral artery and pulse index. The data were analyzed with TCD DWL special software. Direct CVR-CO $\mathrm{C}_{2}$ was defined as the absolute value of blood flow velocity change following each $1 \mathrm{mmHg} \mathrm{PetCO}_{2}$ increase $(\mathrm{cm} / \mathrm{s} / \mathrm{mmHg})$, while relative CVR$\mathrm{CO}_{2}$ (rCVR-CO ${ }_{2}$, which was chosen to record in the present study, hereinafter referred to as $\mathrm{CVR}-\mathrm{CO}_{2}$ ) was defined as the blood flow velocity percent change following each $1 \mathrm{mmHg}$ $\mathrm{PetCO}_{2}$ increase $(\% / \mathrm{mmHg})$, which could be calculated by TCD software.

All patients in the study ( $\mathrm{n}=88)$ were randomly assigned into sevoflurane group (group $\mathrm{S}, \mathrm{n}=44$ ) or propofol group (group $\mathrm{P}, \mathrm{n}=44)$. Random sequence was generated by Excel software (2010; Microsoft, Redmond, WA, USA) on the computer. Then some opaque, sealed envelopes received the random number in advance and were opened sequentially, only after the patient's name was written on the appropriate envelope. Different doctors implemented patients' enrolment, assignment and anesthesia management.

During the process, patients who were enrolled were blinded. Then, BP, HR, NI and CVR-CO 2 were recorded before induction (baseline) in the operation room. In group $\mathrm{S}$, $0.1 \mu \mathrm{g} / \mathrm{kg}$ sulfentanil, $1 \mathrm{mg} / \mathrm{kg}$ lidocaine, $2 \mathrm{mg} / \mathrm{kg}$ propofol and $0.6 \mathrm{mg} / \mathrm{kg}$ rocuronium bromide were applied for induction, and $1.5 \%-2.5 \%$ (end-tidal concentration) sevoflurane with $0.1-1.0 \mu \mathrm{g} / \mathrm{kg} / \mathrm{min}$ remifentanil was applied during surgery. In group P, $0.1 \mu \mathrm{g} / \mathrm{kg}$ sulfentanil, $1 \mathrm{mg} / \mathrm{kg}$ lidocaine, $0.6 \mathrm{mg} / \mathrm{kg}$ rocuronium bromide and $4 \mu \mathrm{g} / \mathrm{mL}$ (in plasma) 
propofol target-controlled infusion was applied for induction, and 3-4 $\mu \mathrm{g} / \mathrm{mL}$ (in plasma) propofol target-controlled infusion with $0.1-1.0 \mu \mathrm{g} / \mathrm{kg} / \mathrm{min}$ remifentanil was applied during surgery. NI monitoring was conducted in the patients to maintain an appropriate anesthetic depth during surgery (about stage D0-E1, 64-20) in both groups. After induction, one end of the $\mathrm{PetCO}_{2}$ monitoring tube was connected to the endotracheal tube, while the other end was still attached to TCD. Then, respiratory support was provided by mechanical ventilation (volume-controlled ventilation, frequency: 12-20 bpm, tidal volume: $8-10 \mathrm{~mL} / \mathrm{kg}$ ). Then, besides baseline CVR- $\mathrm{CO}_{2}$ mentioned above, $\mathrm{CVR}-\mathrm{CO}_{2}$ was also taken 5 minutes after tracheal intubation (before pneumoperitoneum) and 5 minutes during pneumoperitoneum, respectively. During the process, decreasing tidal volume $(6-8 \mathrm{~mL} / \mathrm{kg})$ and respiratory frequency $(6-10 \mathrm{bpm})$ were used to increase patients' $\mathrm{PetCO}$ for a short time with $\mathrm{SpO}_{2}$ being maintained unchanged.

As mentioned previously, CVR decrease might have correlation with impaired cognitive function. ${ }^{12-14}$ Therefore, MMSE was tested to evaluate patients' cognitive function before surgery (baseline) and 24 hours after surgery, respectively.

Registration number: ChiCTR-IPR-15007377.

URL: http://www.chictr.org.cn/showprojen.aspx? proj=12085.

\section{Statistical analysis}

The sample size was estimated by the software PASS8.03 (NCSS LLC, Kaysville, UT, USA), and the estimation indicated that 41 patients in group $\mathrm{S}$ and 42 patients in group $\mathrm{P}$ would be sufficient to detect a difference between $\mathrm{CVR}-\mathrm{CO}_{2}$ at baseline and that during pneumoperitoneum, respectively. Statistical analysis was performed using SPSS for Windows 22.0 (IBM Corporation, Armonk, NY, USA). The normal distribution test was conducted in quantitative data. The normal distribution data were presented as mean $\pm \mathrm{SD}$, and compared using independent-samples $t$-test between groups $\mathrm{S}$ and $\mathrm{P}$. The non-normal distribution data were presented as median (first quartile, third quartile), and compared using Mann-Whitney non-parameters tests between groups S and P. The categorical data were presented as frequency and compared using chi-square test. In either group, data taken at baseline, before pneumoperitoneum and during pneumoperitoneum were compared using Wilcoxon signed rank test. Spearman correlation analysis was conducted between MBP and CVR-CO $\mathrm{CO}_{2} . P<0.05$ was considered to be statistically significant in all the tests above.

\section{Results General information}

In the present study, 88 patients were enrolled. As illustrated in Table 1, there was no significant difference between the 2 groups in age, gender, body mass index (BMI), American Society of Anesthesiologists (ASA) grade, anesthesia duration and fluid infusion (Table $1, P>0.05$ ).

\section{Cerebrovascular reactivity to carbon dioxide}

The values of CVR-CO $\mathrm{C}_{2}$ at baseline, before pneumoperitoneum and during pneumoperitoneum in either group were compared. As illustrated in Table 2, CVR-CO 2 before pneumoperitoneum was significantly higher than that at baseline in both groups $(P<0.01)$. During pneumoperitoneum, CVR$\mathrm{CO}_{2}$ was significantly higher than that at baseline only in group $\mathrm{S}(P<0.05)$, but not in group $\mathrm{P}(P>0.05)$, which means sevoflurane could maintain $\mathrm{CVR}-\mathrm{CO}_{2}$ at a higher level during pneumoperitoneum, while propofol could not. Therefore, the changing trends of CVR-CO $\mathrm{C}_{2}$ were also different in the 2 groups during the maintenance phase of anesthesia and pneumoperitoneum.

\section{Mean blood pressure and $\mathrm{CVR}-\mathrm{CO}_{2}$}

MBP represents the average arterial pressure during a single cardiac cycle. ${ }^{17}$ The values of MBP at baseline and before pneumoperitoneum were compared. As illustrated in Table 3, in either group, MBP before pneumoperitoneum was significantly lower than that at baseline $(P<0.01)$, but there was no significant difference between MBP during pneumoperitoneum and at baseline $(P>0.05)$. The changing trends of MBP were the same in both groups.

The correlation indexes (r) between $\mathrm{MBP}$ and $\mathrm{CVR}-\mathrm{CO}_{2}$ are shown below, which indicates that there was no significant correlation between MBP and CVR-CO $(P>0.05$, Table 4).

Table I Characteristics of patients

\begin{tabular}{llll}
\hline Variables & $\begin{array}{l}\text { Sevoflurane } \\
\text { group }(\mathbf{n = 4 4 )}\end{array}$ & $\begin{array}{l}\text { Propofol } \\
\text { group }(\mathbf{n}=\mathbf{4 4})\end{array}$ & P-value \\
\hline Age (years) & $45.07 \pm 12.12$ & $44.20 \pm 12.87$ & 0.353 \\
Sex (M/F) & $22 / 22$ & $21 / 23$ & $0.83 I$ \\
BMI $\left(\mathrm{kg} / \mathrm{m}^{2}\right)$ & $24.64 \pm 3.75$ & $24.28 \pm 3.17$ & 0.220 \\
ASA grade (I/II) & $34 / 10$ & $35 / 9$ & 0.796 \\
Anesthesia duration (min) & $65.05 \pm 7.05$ & $66.40 \pm 4.60$ & 0.750 \\
Fluid infusion $(\mathrm{mL})$ & $500.65 \pm 276.93$ & $500.74 \pm 280.05$ & 0.643 \\
\hline
\end{tabular}

Note: Data presented as mean $\pm S D$.

Abbreviations: M, male; F, female; BMI, body mass index; ASA, American Society of Anesthesiologists. 
Table $2 \mathrm{CVR}-\mathrm{CO}_{2}$ before and during pneumoperitoneum compared with baseline

\begin{tabular}{llll}
\hline Group & Baseline & Before pneumoperitoneum & During pneumoperitoneum \\
\hline Sevoflurane group $(n=44)$ & $3.76(2.56,5.07)$ & $4.63(3.59,6.95)^{* *}$ & $4.29(2.98,6.32)^{*}$ \\
Propofol group $(n=44)$ & $4.04(2.97,5.09)$ & $4.67(3.56,6.12)^{*}$ & $3.91(3.47,6.00)$ \\
\hline
\end{tabular}

Notes: Data presented as median (first quartile, third quartile); the unit of $\mathrm{Vmean}-\mathrm{CO}_{2}$ is $\% / \mathrm{mmHg}$. $* \mathrm{P}<0.05$, $* * P<0.0 \mathrm{I}$ in comparison with baseline.

Abbreviation: $\mathrm{CVR}-\mathrm{CO}_{2}$, cerebrovascular reactivity to carbon dioxide.

\section{Cognitive function}

As illustrated in Table 5, in either group, there was no significant difference between MMSE scores at baseline and 24 hours after surgery $(P>0.05)$.

\section{Discussion}

Laparoscopic surgery is one of the most common surgeries performed in patients of different age groups, ${ }^{18}$ and during laparoscopic surgeries, intra-abdominal pressure increase could change hemodynamics and have effects on cerebral circulation. ${ }^{19}$ The present study investigated the effects of inhaled anesthetic sevoflurane and intravenous anesthetic propofol on $\mathrm{CVR}-\mathrm{CO}_{2}$ during laparoscopic surgery and compared the changing trends of CVR- $\mathrm{CO}_{2}$ during anesthesia maintenance of the 2 strategies. The results show that in either group, $\mathrm{CVR}-\mathrm{CO}_{2}$ before pneumoperitoneum was significantly higher than baseline. During pneumoperitoneum, sevoflurane maintained a higher level of CVR-CO than baseline, but propofol did not, which indicates that 0.5-1.5 MAC sevoflurane could be a better strategy for the patients with decreased CVR-CO ${ }_{2}$ levels (such as cerebrovascular diseases) during laparoscopic surgery. Besides, neither of the 2 anesthesia methods had significant effects on patients' postoperative cognitive function.

A previous study shows that compared with control group, CVR-CO $\mathrm{C}_{2}$ was preserved in patients who inhaled 1.2 MAC sevoflurane. However, whether CVR- $\mathrm{CO}_{2}$ increased or decreased was not observed in that study. ${ }^{20} \mathrm{In}$ the present study, CVR- $\mathrm{CO}_{2}$ increased after induction and maintained at a higher level before and during pneumoperitoneum. The mechanism of that could include the following aspects: First, $\mathrm{CVR}-\mathrm{CO}_{2}$ is closely related to the function of small vessels in brain. A previous study shows that the effect of anesthetics on CBF depends on the balance of 2 factors.
The first factor is the direct vasoconstriction or vasodilation effect of the anesthetic and the second is the indirect vasoconstriction due to the decrease in cerebral metabolic rate of oxygen $\left(\mathrm{CMRO}_{2}\right) .{ }^{21}$ The direct vasodilation of inhaled anesthetics is stronger than intravenous anesthetic, ${ }^{22}$ which makes cerebral-resistant vessels' response to $\mathrm{PaCO}_{2}$ more easy. This could partially explain why CVR- $\mathrm{CO}_{2}$ during pneumoperitoneum increased compared with baseline in group S. Second, autonomic nervous function is an influence factor in the regulation of CVR- $\mathrm{CO}_{2}{ }^{6}{ }^{6} \mathrm{~A}$ study shows that the decrease in CVR in patients with lacunar infarct related to the decrease in parasympathetic activity, which could also regulate systemic vascular activity. ${ }^{6}$ The parasympathetic activity/ sympathetic activity ratio (high frequency/low frequency ratio in measurement of HR variability) increased after induction of general anesthesia and decreased during pneumoperitoneum, and the intra-abdominal pressure could increase sympathetic cardiac activity. ${ }^{23}$ In the present study, CVR$\mathrm{CO}_{2}$ increased after anesthesia induction, which might result from the increase in parasympathetic activity/sympathetic activity ratio. Due to the opposite effect of intra-abdominal pressure increase, pneumoperitoneum could decrease CVR$\mathrm{CO}_{2}$. Thus, the higher level of CVR-CO during pneumoperitoneum in group $\mathrm{S}$ should be attributed to the balance of sevoflurane and intra-abdominal pressure, which also indicates that sevoflurane could increase $\mathrm{CVR}-\mathrm{CO}_{2}$ during laparoscopic surgery. Third, cerebral autoregulation (CA) is defined as a characteristic that $\mathrm{CBF}$ changed following $\mathrm{BP}$ through vasodilation or vasoconstriction in brain, which reflects contractility of cerebral small vessels. At physiological status, the dilation of cerebral small vessels is the highest when MBP is $\leq 60 \mathrm{mmHg} .{ }^{24} \mathrm{~A}$ previous study shows that sevoflurane and isoflurane have vasodilatory effects on cerebral artery in patients with spine surgery ${ }^{25}$ In the present

Table 3 MBP before and during pneumoperitoneum compared with baseline

\begin{tabular}{llll}
\hline Group & Baseline & Before pneumoperitoneum & During pneumoperitoneum \\
\hline Sevoflurane group $(n=44)$ & $85(90,93)$ & $78(71,84)^{* *}$ & $85(77,93)$ \\
Propofol group $(n=44)$ & $88(81,98)$ & $79(73,89)^{* *}$ & $90(84,97)$ \\
\hline
\end{tabular}

Notes: Data presented as median (first quartile, third quartile); the unit of $\mathrm{MBP}$ is $\mathrm{mmHg} . * * P<0.01$ in comparison with baseline.

Abbreviation: MBP, mean blood pressure. 
Table 4 Correlations between MBP and CVR-CO

\begin{tabular}{llll}
\hline Group & Baseline & Before pneumoperitoneum & During pneumoperitoneum \\
\hline Sevoflurane group $(n=44)$ & -0.009 & -0.014 & 0.017 \\
Propofol group $(n=44)$ & 0.036 & 0.095 & -0.044 \\
\hline
\end{tabular}

Abbreviations: $\mathrm{CVR}-\mathrm{CO}_{2}$, cerebrovascular reactivity to carbon dioxide; MBP, mean blood pressure.

study, CVR- $\mathrm{CO}_{2}$ increased significantly during anesthesia and pneumoperitoneum without $\mathrm{BP}$ change in group $\mathrm{S}$, and there is no significant correlation between $\mathrm{CVR}-\mathrm{CO}_{2}$ and $\mathrm{BP}$, which indicates that $\mathrm{BP}$ and $\mathrm{CA}$ may not be the main affecting factors for the $\mathrm{CVR}-\mathrm{CO}_{2}$ during sevoflurane maintenance.

Propofol was a commonly used intravenous anesthetic. In the present study, it could not maintain a relatively higher level of CVR- $\mathrm{CO}_{2}$ during pneumoperitoneum as sevoflurane did, and the underlying mechanism may also include several aspects: First, a study shows that propofol could reduce $\mathrm{CMRO}_{2}$ by $35 \%$, which means the indirect vasoconstriction of propofol is stronger than inhaled anesthetics. ${ }^{22}$ As a result, the vasoconstriction of propofol could make cerebral-resistant vessels' response to $\mathrm{PaCO}_{2}$ harder, and decreases CVR-CO Second, the increase in intra-abdominal pressure could also decrease $\mathrm{CVR}-\mathrm{CO}_{2}$ through affecting the parasympathetic activity/sympathetic activity ratio ${ }^{23}$ therefore, the decrease in $\mathrm{CVR}-\mathrm{CO}_{2}$ during pneumoperitoneum was attributed to the effects of both propofol and intra-abdominal pressure. Third, propofol has been reported to increase the contraction of cerebral-resistant vessels, which means that it could change the adjusting range of $\mathrm{CA}$ and the dilation of cerebralresistant vessels is the highest when MBP is $<90 \mathrm{mmHg}{ }^{26}$ But in the present study, MBP during pneumoperitoneum was maintained at the level of $90 \mathrm{mmHg}$, which indicates that BP and CA were not the main affecting factors for the CVR-CO $\mathrm{CO}_{2}$ during propofol maintenance.

During the measurement process, the changing range of $\mathrm{PetCO}_{2}$ needed to be considered, because the effects of the same anesthetics on $\mathrm{CVR}-\mathrm{CO}_{2}$ were different at hypercapnia or hypocapnia. ${ }^{22}$ Due to the stronger vasoconstriction of propofol, $\mathrm{CVR}-\mathrm{CO}_{2}$ was not affected apparently by propofol at hypocapnia. ${ }^{22}$ On the contrary, $\mathrm{CVR}-\mathrm{CO}_{2}$ was not affected apparently by high-dose inhaled anesthetics ( $>1$ MAC) at hypercapnia due to its stronger vasodilation..$^{22} \mathrm{In}$ this present

Table 5 Comparisons of MMSE scores at different time points

\begin{tabular}{lll}
\hline Group & Baseline & 24 hours after surgery \\
\hline Sevoflurane group $(n=44)$ & $29(28,29)$ & $28(28,29)$ \\
Propofol group $(n=44)$ & $28(28,29)$ & $28(27,29)$ \\
\hline
\end{tabular}

Note: Data presented as median (first quartile, third quartile). Abbreviation: MMSE, Mini-Mental State Examination. study, we collected the data at eucapnia $(30-40 \mathrm{mmHg}$ $\mathrm{PetCO}_{2}$ ) to calculate $\mathrm{CVR}-\mathrm{CO}_{2}$, which excluded interference of hypercapnia or hypocapnia.

In the present study, the correlation between BP and CVR- $\mathrm{CO}_{2}$ was analyzed. A previous study shows that BP might have effect on $\mathrm{CVR}-\mathrm{CO}_{2} \cdot{ }^{27}$ When MBP increased from 80 to $100 \mathrm{mmHg}, \mathrm{CVR}-\mathrm{CO}_{2}$ in patients under sevoflurane or propofol anesthesia increased significantly. ${ }^{28}$ Another animal experiment shows that $\mathrm{CVR}-\mathrm{CO}_{2}$ was zero when MBP decreased to $40 \mathrm{mmHg}{ }^{27} \mathrm{The}$ possible reason was that the dilation of cerebral-resistant vessels was the highest when MBP was less than the lower limit of CA. In this present study, the results show no significant correlation between $\mathrm{BP}$ and $\mathrm{CVR}-\mathrm{CO}_{2}$ at baseline, before pneumoperitoneum and during pneumoperitoneum (Table 4), which indicates that even within physiological range, $\mathrm{BP}$ is not the main factor affecting $\mathrm{CVR}-\mathrm{CO}_{2}$ during laparoscopic surgery.

It has been reported that $\mathrm{CVR}-\mathrm{CO}_{2}$ correlates with cognitive function, ${ }^{12-14}$ so the present study also observed the MMSE scores of patients before and after surgery, and the results showed no obvious postoperative cognitive dysfunction with either inhaled or intravenous anesthesia.

Although the study investigated the effect of anesthetics on cerebral circulation and revealed the differences between inhaled and intravenous anesthetics, there are several limitations. First, the surgery durations in the study were short (about 1-2 hours) and the average ages of patients were only 44-45 years. Relatively young patients were enrolled because estimating changing trend of CVR-CO2 during anesthesia needs to exclude other influencing factors, such as advanced age, as much as possible. However, the present study could not provide sufficient evidence to show which anesthetic is better for cognitive function protection. Second, the present study just provided intraoperative CVR-CO2 data, but postoperative data collection and longer follow-up visit would be valuable to reveal patients' long-term prognosis, which needs to be further investigated. Finally, the present study applied intravenous induction in both groups, which may affect the results. Therefore, sevoflurane inhalation induction would be another option in sevoflurane group to exclude the effects of intravenous anesthetic in inhaled anesthetic group. 


\section{Conclusion}

The present study supplies a possible method to reveal the effect of anesthetics on cerebral circulation, which is direct and convenient. And the results showed that in patients undergoing laparoscopic cholecystectomy, inhaled anesthetic sevoflurane could maintain a higher level of CVR-CO $\mathrm{CO}_{2}$ during anesthesia and pneumoperitoneum stage, while intravenous anesthetic propofol could only maintain a similar level of CVR-CO $\mathrm{C}_{2}$ with baseline during pneumoperitoneum stage, which indicates that the compensatory vasodilation ability of cerebral small vessels is better during sevoflurane anesthesia. Therefore, in patients with impaired cerebrovascular reserve capacity, such as cerebrovascular disease patients, inhaled anesthetic could be a priority strategy for anesthesia maintenance to improve the compensatory vasodilation ability of cerebral small vessels during surgery.

\section{Acknowledgments}

The present study was supported by the Capital Foundation for Medical Research and Development (No 2011-4023-04), and Key Research Foundation from Peking University Third Hospital.

\section{Disclosure}

The authors report no conflicts of interest in this work.

\section{References}

1. Boles Ponto LL, Magnotta VA, Moser DJ, Duff KM, Schultz SK. Global cerebral blood flow in relation to cognitive performance and reserve in subjects with mild memory deficits. Mol Imaging Biol. 2006; 8(6):363-372.

2. Matta BF, Lam AM, Mayberg TS, Eng CC, Strebel S. Cerebrovascular response to carbon dioxide during sodium nitroprusside- and isofluraneinduced hypotension. Br J Anaesth. 1995;74(3):296-300.

3. Likitjaroen Y, Suwanwela NC, Phanthumchinda K. Vasoreactivity induced by acetazolamide in patients with vascular dementia versus Alzheimer's disease. J Neurol Sci. 2009;283(1-2):32-35.

4. Dlamini N, Yau I, Westmacott R, et al. Cerebrovascular reactivity and intellectual outcome in childhood stroke with transient cerebral arteriopathy. Pediatr Neurol. 2017;69:71-78.

5. Goode SD, Altaf N, Munshi S, MacSweeney ST, Auer DP. Impaired cerebrovascular reactivity predicts recurrent symptoms in patients with carotid artery occlusion: a hypercapnia BOLD fMRI study. AJNR Am J Neuroradiol. 2016;37(5):904-909.

6. Intharakham K, Suwanprasert K, Muengtaweepongsa S. Correlation between decreased parasympathetic activity and reduced cerebrovascular reactivity in patients with lacunar infarct. Curr Neurovasc Res. 2017; 14(1):65-70.

7. Glodzik L, Randall C, Rusinek H, de Leon MJ. Cerebrovascular reactivity to carbon dioxide in Alzheimer's disease. J Alzheimers Dis. 2013; 35(3):427-440.

8. Di Marco LY, Farkas E, Martin C, Venneri A, Frangi AF. Is vasomotion in cerebral arteries impaired in Alzheimer's disease? J Alzheimers Dis. 2015;46(1):35-53.
9. Haight TJ, Bryan RN, Erus G, et al. Vascular risk factors, cerebrovascular reactivity, and the default-mode brain network. Neuroimage. 2015;115:7-16.

10. Richiardi J, Monsch AU, Haas T, et al. Altered cerebrovascular reactivity velocity in mild cognitive impairment and Alzheimer's disease. Neurobiol Aging. 2015;36(1):33-41.

11. Smolinski L, Czlonkowska A. Cerebral vasomotor reactivity in neurodegenerative diseases. Neurol Neurochir Pol. 2016;50(6):455-462.

12. Shim Y, Yoon B, Shim DS, Kim W, An JY, Yang DW. Cognitive correlates of cerebral vasoreactivity on transcranial Doppler in older adults. J Stroke Cerebrovasc Dis. 2015;24(6):1262-1269.

13. Zavoreo I, Basic Kes V, Lisak M, Marsic N, Ciliga D, Trost Bobic T. Cognitive decline and cerebral vasoreactivity in asymptomatic patients with severe internal carotid artery stenosis. Acta Neurol Belg. 2013; 113(4):453-458.

14. Ito Y, Matsumaru Y, Suzuki K, Matsumura A. Impaired cognitive function due to cerebellar infarction and improvement after stent-assisted angioplasty for intracranial vertebral artery stenosis - case report. Neurol Med Chir (Tokyo). 2010;50(2):135-138.

15. Sam K, Conklin J, Holmes KR, et al. Impaired dynamic cerebrovascular response to hypercapnia predicts development of white matter hyperintensities. Neuroimage Clin. 2016;11:796-801.

16. Schmidt R, Schmidt H, Kapeller P, et al. The natural course of MRI white matter hyperintensities. J Neurol Sci. 2002;203-204:253-257.

17. Zheng L, Sun Z, Li J, et al. Pulse pressure and mean arterial pressure in relation to ischemic stroke among patients with uncontrolled hypertension in rural areas of China. Stroke. 2008;39(7):1932-1937.

18. Duca S, Iancu C, Bala O, et al. Mini-invasive treatment of complications following laparoscopic cholecystectomy. Acta Chir Belg. 2004; 104(3):309-312.

19. Pelizzo G, Bernardi L, Carlini V, et al. Laparoscopy in children and its impact on brain oxygenation during routine inguinal hernia repair. J Minim Access Surg. 2017;13(1):51-56.

20. Cho S, Fujigaki T, Uchiyama Y, Fukusaki M, Shibata O, Sumikawa K. Effects of sevoflurane with and without nitrous oxide on human cerebral circulation. Transcranial Doppler study. Anesthesiology. 1996;85(4): 755-760.

21. Lam AM, Matta BF, Mayberg TS, Strebel S. Change in cerebral blood flow velocity with onset of EEG silence during inhalation anesthesia in humans: evidence of flow-metabolism coupling? J Cereb Blood Flow Metab. 1995;15(4):714-717.

22. Mariappan R, Mehta J, Chui J, Manninen P, Venkatraghavan L. Cerebrovascular reactivity to carbon dioxide under anesthesia: a qualitative systematic review. J Neurosurg Anesthesiol. 2015;27(2):123-135.

23. Sato N, Kawamoto M, Yuge O, et al. Effects of pneumoperitoneum on cardiac autonomic nervous activity evaluated by heart rate variability analysis during sevoflurane, isoflurane, or propofol anesthesia. Surg Endosc. 2000;14(4):362-366.

24. Meng L, Gelb AW. Regulation of cerebral autoregulation by carbon dioxide. Anesthesiology. 2015;122(1):196-205.

25. Matta BF, Heath KJ, Tipping K, Summors AC. Direct cerebral vasodilatory effects of sevoflurane and isoflurane. Anesthesiology. 1999;91(3): 677-680.

26. Lagerkranser M, Stange K, Sollevi A. Effects of propofol on cerebral blood flow, metabolism, and cerebral autoregulation in the anesthetized pig. J Neurosurg Anesthesiol. 1997;9(2):188-193.

27. Artru AA, Colley PS. Cerebral blood flow responses to hypocapnia during hypotension. Stroke. 1984;15(5):878-883.

28. McCulloch TJ, Visco E, Lam AM. Graded hypercapnia and cerebral autoregulation during sevoflurane or propofol anesthesia. Anesthesiology. 2000;93(5):1205-1209. 
Therapeutics and Clinical Risk Management

Dovepress

\section{Publish your work in this journal}

Therapeutics and Clinical Risk Management is an international, peerreviewed journal of clinical therapeutics and risk management, focusing on concise rapid reporting of clinical studies in all therapeutic areas outcomes, safety, and programs for the effective, safe, and sustained use of medicines. This journal is indexed on PubMed Central, CAS,
EMBase, Scopus and the Elsevier Bibliographic databases. The manuscript management system is completely online and includes a very quick and fair peer-review system, which is all easy to use. Visit http://www.dovepress.com/testimonials.php to read real quotes from published authors.

Submit your manuscript here: http://www.dovepress.com/therapeutics-and-clinical-risk-management-journal 